\title{
On the Solvability of Transonic Potential Flow Problens
}

\author{
M. Feistauer and J. Ňečas
}

To Prof. Dr. Herbert Beckert on the occasion of his 65th birthday

Wir betrachten Potentialströmungen im schallnahen Bèreich. Die Gleichung für das Geschwindigkeitspotential, die eine wirbelfreic, ideale Strömung beschreibt, ist nichtlinear, von,zweiter Ordnung und vom gemischten Typ. Bisher ist die Existenz von Lösungen noch nicht bewiesen worden, es gibt nur eine Reihe von numerischen Methoden zur Berèchnung solcher Uberschallströmungen.

Mit Hilfe des Sekantenverfahrens und einem bequemen Prinzip der optimalen Steuerung konstruieren wir hier ein Funktional $\dot{\psi}$, dessen Minimierung zur Lösung des Ausgangsproblems äquivalent ist. Da Schocks auftreten, d. h. Sprünge der Geschwindigkeit, der Dichte und des Drucks, betrachten wir schwache Lösungen im Raum $W^{1,2}(\Omega)$. Vom physikalischen Standpunkt aus ist die Entropiebedingung entlang des Schocks sehr wichtig. Es gibt verschiedene Möglichkeitèn, um diese Bedingung numerisch zu berücksichtigen. Wir betrachten hier eine vereinfuchte Form dieser Bedingung, die von Glowinski, Pironneau und anderen benutzt wurde und schlagen gleichzeitig eine kompliziertere Formulierung vor, die sehr natürlich ist. .

Wir zeigen, da $\beta$ diese Bedingungen die zunächst fehlende Kompaktheit kompensieren und können so die Existenz der Lösung im folgenden Sinn beweisen: Wenn die Minimalfolge für. das Funktional $\psi$ der Entropiebedingung genügt und die Geschwindigkeit beschränkt ist, wenn feruer diese Folge schwach gegen die Funktion $u$ konvergiert, dann liegt starke Konvergenz vòr, und $u$ ist eine Lösung des Probleḿs im Überschallbereich.

Diese Arbeit enthält ferner einige Resultate bezüglich dès Unterschallbereichs und der Regularität der Minimalfolge.

Статья посвлщена изучению разрешимости задачи околозвукового потенциального течения. Уравнение безвихреного, иевязкого, 'околозвукового течения нелинейно, второго порндка и смешанного типа. Существует ряд численных методов основанных на методах конечных разностей и конечных элементов для расчета онолозвуконых течений. Но до сих пор пе доказано существование решения этоп задачи.

Здесь, воспользуя метод Качанова п удобный принцип оптимального упіравления, мы нонструируем функционаз $\psi$, минимнзацня которого эквивалентна решению задачи. Так как разрывы скорости, давления и плотности встречаются в околозвуковых течениях, мы рассматринаем спабые решения из пространства $W^{1,2}(\Omega)$. С физнческон точки зрения очень важно условие энтропии на разрыве. Существуют разные прнемы изу-чения этого условия в численных метолах. Здесь мы используем простую форму Гловннсного, ПІиронно и других и кроме того ввотим новую естественную, но более сложную формулировку этого условия.

В статье показа̇н, что эти условия компенсируют отсутстиуюшую компактность и позволяют показать существование решения в слејуюшем смысле: Если минимизирующая последовательность функционала $\psi$ выполняет (апостериори) условия әитропии II ограниченно ї скорости и сходится слабо к фуннции $u$, то она сходится к $u$ сильно и $u$ явјьяется решением задачи.

Кроме того в статье доказай нокоторые результаты касающиеся дозвуковых тече.' ний и регулнрности минимизирующей последовательности.

The paper is devoted to the study of the solvability of transonic potential flow problems. The velocity potential equation governing irrotational non-viscous transonic flows is nonlinaer, 
second order and of mixed type. There exist a series of numerical methods for the solution of the transonic flows. However, the existence of the solution has not yet been proved.

Here, with the use of the secant-modulus method and i convenient optimal control principle, we,construct a functional $\psi$, whose minimization is equivalent to the solution of the problem. Since the so-called shocks, represented by jumps in the velocity, density and pressure, occur in the flow field, we consider weak solutions from the space $W^{1,2}(\Omega)$. From the physical point of view the entropy condition across the shock is very important. There exist various approaches how to embody this condition into the numerical method. Here we consider its simplified version by Glowinski, Pironneau etc. and besides, we propose its new natural, more complex formulation.

We show that these conditions introduce the missing compactness into the problem and allow to prove the existence of the solution in the following sense: If the minimizing sequence of the functional $\psi$ satisfies (a posteriori) the entropy and bounded velocity conditions and converges weakly to a function $u$, then it converges strongly to $u$ and $u$ is a solution of the transonic flow problem.

The paper contains also some results concerning subsonic flows and the regularity of the minimizing sequence.

\section{Introduction}

The study of transonic flows is the centre of general attention for many specialists. It has a great importance in the design of high speed aircrafts and highly efficient turbines, compressórs and other blade machines with large output.

There exist several mathematical models for the investigation of transonic flows. Very often we meet the model of an irrotational, steady, non-viscous flow, since it is represented by relatively simple equations and gives good results for subsonic strcam fields via velocity potential or stream function formulations (cf. e.g. $[10,12,31]$ ).

In contrast to subsonic irrotational non-viscous flows, where the solvability of boundary value problems for velocity potential (or stream function) can be proved by the monotone operator theory, the mathematical study of transonic flow problems is very difficult. The potential equation is nonlinear and of mixed type, since it is elliptic in a subsonic region and hyperbolic in a supersonic region. 'The boundary between these regions is not known in advance and is obtained together with the sought solution. Moreover, passing across this boundary is not continuous in general, but it is connected with jumps (called shocks or shock waves) in the velocity, density and pressure. Hence, the concept of a classical solution has no sense and it is necessary to consider generalized weak solutions. If we introduce a weak formulation similarly as in elliptic problems, then the corresponding operator is not monotone and has no compactness properties which would allow the application of the monotone and pseudomonotone operator theory or some compactness results for proving the solvability. 'Iherefore, up to now, there exist no results concerning the existence or uniqueness of the solution to the transonic potential flow problems.

In contrast to the lack of theoretical results, we:can meet a.lot of numerical methods for modelling transonic two- and also three-dimensional streain fields past airfoils, cascades of profiles or blades and through channels. Most of these numerical approaches are based on finite-difference methods combined with a successive line over relaxation (SLOR). They are connected with the names Cole, Murman, GakAbedian, Kor:; Jameson, Kozel, Polášez and others $([6,16,20,21,23,24]$ and the bibliographies therein). Some authors use multigrid techniques for improving the convergence (see e.g. [2,22]). Remarkable results were obtained by Glowrsskr, Pironneau, Bristeau, Periadx, Perrier and Poirier $([3,4,17-19,32]$ and others) who use the finite element method, least squares and conjugate gradients.

$\therefore \quad$ Other finite element techniques can be found e.g. in $[5,7]$. 
Numerical results of Glowisski, PrRonsead etc. show that the solutions of the discrete potential transonic flow problems possess nonuniqueness of the solution and that the nonphysical solutions with expansion shocks occur. These solutions are usually very attractive for iterative processes (cf. e.g. $[18,32]$ ). Similar experience with the nonphysical solutions was obtained by Ferstauer and Oršulík [8, 30]. In order to avoid the solutions with nonphysical shocks, we must assume that the velocity decreases across the shock (entropy condition). This condition is embodied into the numerical methods hy various ways. In $[16,20,21,23,24]$ the upwind discretization used in the supersonic region causes an artificial viscosity which depresses the nonphysical shocks. In recent papers $[2,5,7]$ an artificial viscosity is introduced by upwinding the density. In $[3,4,17-19,32]$ the entropy condition is considered as a constraint in an optimal control problem and is handled via penalization, regularization, or other optimalization techniques.

Here, in this paper, we try to answer the fundamental question concerning the solvability of the transonic flow problems, formulated for the velocity potential. With the use of the secant modulus methods known also as Katchanov's method, popular in elasticity, we construct a suitable functional whose minimization is equivalent to the solution of the boundary value problem considered. Since this functional is nonconvex, without any compactness properties,. it is impossible to apply some known convex analysis results for proving the convergence of a minimizing sequence to a solution. However, if we assume a posteriori that the elements of this sequence satisfy a convenient entropy condition and some regularity assumptions, then we build the missing compactness into the problem and prove the convergence of this sequence to the solution of the transonic flow problem.

This process is constructive. It can be discretized by the finite element method and used as a basis of a new method for the numerical simulation of the transonic flows. This will be the subject-matter of forthcomming papers.

\section{Fundamental concepts and equations}

Let us consider an irrotational, steady, adiabatic and isentropic flow of a non:viscous, compressible fluid in a bounded domain $\Omega \subset \mathbf{R}_{n}(n=2$ or $n=3)$. We assume that the boundary $\partial \Omega$ of $\Omega$ is Lipschitz-continuous and $\Omega$ is simply connected. It means that every two piecewise differentiable curves connecting in $\Omega$ arbitrary points $x$, $y \in \Omega$ are mutually transformable in $\Omega$ by a homotopy. The closure of $\Omega$ is denoted by $\bar{Q}$.

The flow considered is described by the following equations: .

$$
\begin{aligned}
& \operatorname{div}(\varrho \mathbf{v})=0, \\
& \sum_{j=1}^{n} v_{i} \frac{\partial v_{i}}{\partial x_{j}}=-\frac{1}{\varrho} \frac{\partial p}{\partial x_{i}} ; i=1, \ldots, n, \\
& p=p(\varrho)=c \varrho^{x}, \\
& \operatorname{rot} \mathbf{v}=0
\end{aligned}
$$

considered in $\Omega$. We use the notation: $v$ - velocity vector with the components $v_{1}, \ldots, v_{n}$ in Cartesian coordinates $x_{1}, \ldots, x_{n}$ introduced in $\mathbf{R}_{n}, \grave{\varrho}-$ density, $p-$ pressure. $c>0, \%>1$ are given constants. We assume that $v_{i} ; p, \varrho$ are functions (dependent on $\left.x=\left(x_{1}, \ldots, x_{n}\right) \in \bar{\Omega}\right)$ continuously differentiable in $\bar{\Omega}$. In following 
considerations we shall also admit discontinuities of these quantities. Let us remark that (1.1) is the continuity equation, (1.2) are the Euler equations of motion, (1.3) is the condition of the adiabatic, isentropic process and (1.4) represents the condition of the irrotational flow.

Let us introduce the local speed of sound $a$ by the relation

$$
a^{2}=\frac{d p}{d \underline{Q}}=p^{\prime}
$$

and the so-called pressure function

$$
\mathscr{P}(g)=\int_{e_{e}}^{e} \frac{\dot{p}^{\prime}(\tau)}{\tau} d \tau
$$

We denote by $\varrho_{0}, p_{0}, a_{0}$ the values of the density, pressure and speed of sound, respectively, corresponding to the velocity $v=0$. It is easy. to see that

$$
\operatorname{grad} \mathcal{P}=\frac{1}{\varrho} \operatorname{grad} p
$$

From this, the relation

$$
\sum_{j=1}^{n} v_{j} \frac{\partial \dot{\mathbf{v}}}{\partial x_{j}}=\frac{1}{2} \operatorname{grad} \cdot|\mathbf{v}|^{2}-\dot{\mathbf{v}} \times \operatorname{rot} \mathbf{v}
$$

and (1.4) the identity grad $\left(\mathscr{P}+\frac{1}{2}|v|^{2}\right)=0$ follows; which.implies

$$
\mathcal{P}+\frac{1}{2}|\mathbf{v}|^{2}=0 \text {. }
$$

If we use (1.3), (1.5), (1.6) and (1.9), we derive the relation between the density and. . velocity of the form

$$
\varrho=\varrho_{0}\left(1-\frac{\varkappa-1}{2 a_{0}^{2}}|v|^{2}\right)^{\frac{1}{x-1}}
$$

On the basis of (1.4) and the assumptions concerning the domain $\Omega$ we can introduce the velocity potential $u: \Omega \rightarrow \mathbf{R}_{1}$ such that $\operatorname{grad} u=\nabla u=v$. By substituting into (1.1) we get the equation for the potential $u$ :

$$
\sum_{i=1}^{n} \frac{\partial}{\partial x_{i}}\left[\varrho\left(|\nabla u|^{2}\right) \frac{\partial u}{\partial x_{i}}\right]=0^{\prime}
$$

From (1.10) we see that the density is defined for

If

$$
|v|^{2} \leqq \frac{2 a_{0}^{2}}{x-1}
$$

$$
|\mathbf{v}|^{2} \leqq \frac{2 a_{0}^{2}}{x+1} \quad \text { in } \quad \Omega_{1} \subset \Omega \text {, }
$$

then $|\mathbf{v}| \leqq a$ in $\Omega_{1}$ and we say that the flow is subsonic in $\Omega_{1}$. On the other hand, if ,

$$
|v|^{2}>\frac{2 a_{0}^{2}}{x+1} \text { in } \Omega_{2} \subset \Omega \text {. }
$$


then $|v|>a$ in $\Omega_{2}$ and the flow is supersonic in $\Omega_{2}$. The equation (1.11) is elliptic or hyperbolic in the subsonic or supersonic region, respectively.

It is known, that in a purely subsonic flow, where the equation (1.11) is elliptic, the velocity potential is continuously differentiable. However, if we consider a transonic flow, then the domain $\Omega$ can be divided into a subsonic region $\Omega_{1}$ and a supersonic region $\Omega_{2}$. The boundary between $\Omega_{1}$ and $\Omega_{2}$ contains usually shocks with jumps in $v, p, g$. It means that the velocity potential $u$ is no more continuously differentiable in $\Omega$.

Across the shock we consider Prandtl's conditions

$$
\begin{aligned}
& \left.\frac{\partial u}{\partial t}\right|^{-}=\left.\frac{\partial u}{\partial t}\right|^{+} \\
& \left.\varrho\left(|\nabla u|^{2}\right) \cdot \frac{\partial u}{\partial n}\right|^{-}=\left.o\left(|\nabla u|^{2}\right) \frac{\partial w}{\partial \dot{n}}\right|^{+}
\end{aligned}
$$

where - or + denotes the quantities in front of the shock;or behind the shock; respectively. By $\partial / \partial t$ and $\partial / \partial n$ we denote the derivative with respect to the tangential and normal directions to the shock, respectively. Very' important is the entropy condition across the shock:

$$
|\mathbf{v}|^{-}>|\mathbf{v}|^{+}
$$

(the velocity must decrease). In this paper we shall consider the entropy condition formulated with the use of the velocity potential in the form

$$
\begin{aligned}
& \cdot \int_{\Omega} \varrho^{\prime}\left(|\nabla u|^{2}\right)|\grave{\nabla} u|^{2} \nabla u \cdot \nabla h d x \leqq M \int_{\Omega} h d x \\
& \forall h \in \mathcal{D}(\Omega), \quad h \geqq 0
\end{aligned}
$$

(natural form) and also

$$
\begin{aligned}
& -\int_{S} \nabla u \cdot \nabla h d x \leqq M \int_{\Omega} h d x \\
& \forall h \in \mathcal{D}(\Omega), \quad h \geqq 0
\end{aligned}
$$

(simplified form). We denote by $\mathscr{D}(\Omega)$ the set of all functions from $C^{\infty}(\bar{\Omega})$ with compact supports in $\Omega . M \in \mathbf{R}_{1}$ is a convenient constant. The condition (1.18) was used e.g. in $[3,18,32]$. Its advantage is linearity.

Let us remark that in a real flow the transition across the shock is connected with the increase of the entropy and with the rise of the vorticity. It means that our model - of the irrotational, isentropic flows can be applied, if we confine ourselves to stream fields with the Mach number $\mathrm{M}=|\mathrm{v}| / a<1.6$, where the so-called weak shocks occur only. Then the changes in the entropy and the production of the vorticity on the shocks are negligible.

This is important for the dependence of the density on the velocity. In the follow-ing we shall assume that this dependence is given by a function $\varrho$ with the following properties:

$\varrho$ and $\varrho^{\prime}$ are continuous in $[0,+\infty)$,

$$
\varrho(s)=\varrho_{0}\left(1-\frac{x-1}{2 a_{0}^{2}} s\right)^{\frac{1}{x-1}} \text { for } s \dot{\epsilon}\left[0, s^{*}\right]
$$


with $s^{*} \in\left(\frac{2 a_{0}^{2}}{x+1}, \frac{2 a_{0}^{2}}{x-1}\right)\left(s^{*}\right.$ is close to $\left.\frac{2 a_{0}^{2}}{x-1}\right)$ and

$$
\begin{aligned}
& 0<\varrho_{\infty} \leqq \varrho(s) \leqq \varrho_{0}<+\infty \\
& \left|\varrho^{\prime}(s)(1+s)\right| \leqq c_{0} \\
& \varrho^{\prime}(s) \leqq 0 \quad \text { (fundamental condition) }
\end{aligned}
$$

for all $s \in[0,+\infty) . \varrho_{\infty}, \varrho_{0}$ and $c_{0}$ are constants.

'The existence of such $\varrho$ is evident. It can be obtained e:g. by extending $\varrho \mid\left[0, \frac{1}{2}\left(s^{*}+\frac{2 a_{0}^{2}}{x-1}\right)\right]$ to $[0,+\infty)$ by a positive constant $\varrho_{\infty}=\varrho\left(\frac{1}{2}\left(s^{*}+\frac{2 a_{0}^{2}}{x-1}\right)\right)$ and then, by a suitable smoothing in the interval $\left[s^{*}, \frac{2 a_{0}{ }^{2}}{x-1}\right]$. If $s^{*}$ is close enough to $\frac{2 a_{0}{ }^{2}}{\varkappa-1}$, then for $|\mathrm{v}|^{2} \in\left[0, s^{*}\right]$ the corresponding Mach number varies from 0 to a value $\tilde{\mathbf{M}} \gg 1.6$. Hence, the modification of the function $\varrho$ in a neighbourhood of the point $\frac{2 a_{0}{ }^{2}}{x-1}$ and the extension of $\varrho$ to $[0,+\infty)$ is not significant for the validity of our model from the physical point of view.

In the following, some considerations will be restricted to the stream fields with the velocity satisfying the condition

$$
|v|^{2} \leqq s_{1}<\frac{6 a_{0}^{2}}{x+1} .
$$

If $x=1.4$ (the flow of the air), then $(\mathbf{1 . 2 4})$ represents the restriction to flow fields with $\mathrm{M} \in[0,2.23)$.

\section{Formulation of the boundary value problem}

Since $\partial \Omega$ is Lipschitz-continuous, we cán define the $(n-1)$-dimensional Lebesgue measure $\mu_{n-1}$ on $\partial \Omega$. Let $\left.\partial \Omega=\Gamma_{1} \cup \grave{\Gamma}_{2} \cup S \cup \Omega\right\}$, where $\Gamma_{i}$ and $S$ are open sets in $\partial \Omega$ and $\mu_{n-1}(9)=0$. We shall consider the velocity potential equation

$$
\sum_{i=1}^{2} \frac{\partial}{\partial x_{i}}\left[\varrho\left(|\nabla u|^{2}\right) \frac{\partial u}{\partial x_{i}}\right]=0^{\circ} \text { in } \Omega
$$

(with the function $\varrho$ that has the properties $(1.19)-(1.23)$ ) and the boundary conditions

$$
\begin{aligned}
& u=0 \text { on } I_{1}^{\prime}, \\
& \varrho\left(|\nabla u|^{2}\right) \frac{\partial u}{\partial n}=g \text { on } S \cup I_{2} .
\end{aligned}
$$

If $g=0$ on. $S$ and $g<0$ on $\Gamma_{2}$, then we get the situation corresponding to the flow in a channel whose impermeable walls form the set $S$ and are parallel in a neighbourhood of the outlet $\Gamma_{1}$, which is normal to $S$. $\Gamma_{2}$ denotes the inlet. Usually, we assume that $\mu_{n-1}\left(\Gamma_{1}\right)>0$. Sometimes we also admit the possibility $\mu_{n-1}\left(\Gamma_{1}\right)=0$ and then we consider the boundary condition

$$
\varrho\left(|\nabla u|^{2}\right) \frac{\partial u}{\partial n}=\ddot{g} \quad \text { on } \cdot \partial \Omega
$$


In this case we assume that

$$
\int_{\partial \Omega} g d s=0
$$

- Further, if the shocks occur in the stream field, then we assume that the conditions $(1.15, a-b)$ are satisfied. (The entropy condition will be considered later.)

In order to introduce a weak formulation of this boundary value problem, we define the space

$$
V=\left\{v \in W^{1.2}(\Omega): v=0 \text {, on } \Gamma_{1} \text { in the sense of traces }\right\}
$$

if $\mu_{n-1}\left(I_{1}\right)>0$ and the conditions (2.2) and (2.3) are considered, and

$$
V=\left\{v \in W^{1,2}(\Omega): \int_{\Omega} v d x=0\right\},
$$

if $\mu_{n-1}\left(\Gamma_{1}\right) \doteq 0$ and we use the condition $(2.4): W_{2}^{1}(\Omega)$ is the well-known Sobolev space. (For the definitions of all spaces used, see e.g. the books of NEČs $[27,28]$ ). We assume, that $g \in L^{\infty}\left(\Gamma_{2} \cup S\right)$ (or $g \in L^{\infty}(\partial \Omega)$ ). In both cases (2.6) and (2.7), the space $V$ can be equipped with the norm

$$
\|u\|=\left(\int_{\Omega}|\nabla u|^{2} d x\right)^{1 / 2}
$$

We say that $u$ is a weak solution of the velocity potential problem, if ${ }^{\circ}$.

$$
\begin{aligned}
& u \in V, \\
& \int_{\Omega} \varrho\left(|\nabla u|^{2}\right) \nabla u \cdot \nabla v d x=\int_{\partial \Omega} g v d s \forall v \in V .
\end{aligned}
$$

(We can put e:g. $g=0$ on $\Gamma_{1}$ in the case of the boundary conditions (2.2), (2.3).)

By the use of Green's theorem it is possible to show that both the problem (2.1) to (2.3), $(1: 15, a-b)$ and the problem (2.1), (2.4), (1.15, a-b) are formally equivalent to $(2.9, a-b)$. The details are contained in [30].

Let us put

$$
R(s)=\int_{0}^{s} g(t) d t \text { for } s \in[0,+\infty)
$$

and define the functional $\Phi: V \rightarrow \mathbf{R}_{1}:$

$$
\Phi(u)=\frac{1}{2} \int_{\Omega} R\left(|\nabla u|^{2}\right) d x \text { for } u \in \gamma
$$

Let $u \in V$. By $w=v(u)$ we denote the solution of the linear problem

(a) $w \in V$,

(b) $\cdot \int_{\Omega} \varrho\left(|\nabla u|^{2}\right) \nabla w \cdot \nabla v d x=\int_{\partial \Omega} g v d s \forall v \in V$

and define the functional $\psi: V \rightarrow: \mathbf{R}_{1}$ by the relation

$$
\psi(u)=\Phi(u)-\Phi(w(u))-\int_{\partial \Omega} g u d s+\int_{\partial \Omega} g w(u) d s, \quad u \in V
$$


It is evident that a fixed point $u$ of the mapping $u \rightarrow w(u)$ is a solution of the problem $(2 . \dot{9}, \mathrm{a}-\mathrm{b})$. The fundamental idea how to find this solution $u$ is based on a convenient optimal control principle. Here, we shall minimize the functional $\dot{\psi}$ on the space V. It. means that we seck $u \in V$ such that

$$
\psi(u)=\min _{\xi \in V} \psi(\xi)
$$

If we find this $u$, then we have to verify whether the condition (1.12) (or better (1.24)) and the entropy condition considered, i.e. (1.17) or (1:18) are satisfied, in order to be sure that $u$ is a physical solution.

From the numerical point of view, it will be probably suitable to minimize the functional $\psi$ in the set of all $u \in . V$ satisfying the finite velocity condition (i.e. (1.12) or (1.24)) and the entropy condition ((1.17) or (1.18)).

Reinark 2.15: Studying the channel flow with the supersonic inlet $\Gamma_{2}$, it is necessary to consider both the Neumann condition $\varrho \frac{\partial u}{\partial n} \mid \Gamma_{2}=g$ and the Dirichlet condition $u I_{2}=u_{2}$ (with given $g$ and $u_{2}$ ) at the inlet $\Gamma_{2}$. Then it is convenient to extend . the functional $\psi$ by the identification term

$$
I(u)=\int_{\Gamma_{3}}\left|u \div u^{2}\right|^{2} d s,
$$

added to the right-hand side in (2.13). For simplicity, we shall not deal with this case in the following.

Remark 2.17: The reason for the choice of the functional $\psi$ as the cost function in our optimal control problem will be cleared up in the following section (see Remark 3.27 ).

\section{Secant modulus method}

This method, known also' as Katchanov's method, is described in a series of papers (c.g. [14]), among others also in books [28] and [29]. It plays a fundamental role in our considerations. We shall explicate it in its abstract version according to the cited references.

Let $V$ be a Hilbert space with the norm $\|\cdot\|$ and $\Phi: V \rightarrow \mathbf{R}_{1}$ be a functional that has the Gâteaux differential $D \Phi(u, \cdot)$ at every $u \in V$. For each $u \in V$ let us consider a form $B(u, v, w)$, bilinear and symmetric in $v, w \in V$, with the following properties $(u, v, w \in V)$ :

$$
\begin{aligned}
& |B(u, v, w)| \leqq c_{1}\|v\|\|w\|, \\
& B(u, v, v) \geqq c_{2}\|v\|^{2}, \quad c_{2}>0, \\
& D \Phi(u, v)=B(u, u, v) \\
& \frac{1}{2} B(u, v, v)-\frac{1}{2} B(u, u, u)-\Phi(v)+\Phi(u) \geqq 0 .
\end{aligned}
$$

Let us consider a continuous linear functional $f$ defined on $V$ (i.e. $f \in V_{1}^{*}, V^{*}=$ dual to $V$ ). If $u \in V$, then we denote by $w=w(u)$ the solution of the equation

$$
B(u, w, v)=\langle f, v\rangle \forall v \in V \text {. }
$$


(The symbol $\langle f, v\rangle$ for $f \in V^{*}, v \in V$ denotes the duality between $V$ and $V^{*}$ ). From the Lax-Milgram lemma the existence and uniqueness of such $w$ follow.

Theorem 3.6: Let $\Phi$ and $B$ have the above properties. Then

$$
\frac{1}{2} c_{2}\|u-w(u)\|^{2} \leqq \psi(u):=\dot{\Phi}(u)-\Phi(u(u))-\langle f, u-\dot{v}(u)\rangle .
$$

for every $u \in V$.

Proof: Let us put

$$
\pi(v)=\Phi(u)-\langle f, v\rangle+\frac{1}{2} B(u, \dot{v}, v)-\frac{1}{2} B(u, u, u)
$$

and

$$
C(u) \doteq \Phi(u)-\langle f, u\rangle
$$

Then, from (3.4) for $v:=w=v(u)$ we'get

$$
\begin{aligned}
C(w) & \leqq C(w)+\Phi(u)-\Phi(w)+\frac{1}{2} B(u, w, w)-\frac{1}{2} B(u, u, u) \\
& =\Phi(u)-\langle f, w\rangle+\frac{1}{2} B(u, w, w)-\frac{1}{2} B(u, u, u)=\pi(w) .
\end{aligned}
$$

Further, if we use the last relation, the equation (3.5) (with $v:=u$ or $v:=\dot{w}$ ) and the properties of $B$, then

$$
\begin{aligned}
\pi(w)= & \Phi(u)-\langle f, w\rangle+\langle f, u\rangle-\langle f, u\rangle+\frac{1}{2} B(u, w, w)-\frac{1}{2} B(u, u, u) \\
= & C(u)+B(u, w, u)-B(u, w, w)+\frac{1}{2} B(u, w, w)-\frac{1}{2} B(u, u, u) \\
& =C(u)-\frac{1}{2} B(u, u-w, u-w) \leqq C(u)-\frac{1}{2} c_{2}\|\dot{i}-w\|^{2} .
\end{aligned}
$$
Hence, $C(w) \leqq \pi(w) \leqq C(u)-\frac{1}{2} c_{2}\|u-w\|^{2}$, which immediately gives the assertion
of the theorem

Theorem 3.12: If $\Phi$ and $B$, have the above properties and moreover, if

$$
D \Phi(u+h, h)-D \Phi(u, h) \geqq c_{3}\|h\|^{2} \forall u, h \in \mathrm{K}
$$

with a constant $c_{3}>0$ (independent of $\left.u, h\right)$, then there exists a unique critical point $u$ of the functional $C, C(\dot{u})=\Phi(u)-\langle f, u\rangle$. If we define a sequence $\left\{u_{n}\right\}_{n=0}^{\infty}$ by the iterative process " $u_{0} \in V$ (is arbitrary) and $u_{n+1}=w\left(u_{n}\right)$ for $n \geqq 0$ ", then $u_{n} \rightarrow u$ in $V$, if $n \rightarrow+\infty$, and $u$ is a unique minimum point of $C$.

Proof:-The assumptions layed on $\Phi$ imply that the functional $C$ is coercive, weakly lower semi-continuous, strictly convex and bounded from below. Hencé, there exists exactly one critical point $u$ of $C$. (See e.g. [15] or [33].) Moreover, $u$ is its mini- 
mum point. Now, we have $D \Phi(u, h)=\langle f, h\rangle$ for all $h \in V$ and

$$
\begin{aligned}
c_{3}\left\|u_{n}-u\right\|^{2} & \leqq D \Phi\left(u_{n}, u_{n}-u\right)-D \Phi\left(u, u_{n}-u\right) \\
& =B\left(u_{n}, u_{n}, u_{n}-u\right)-\left\langle f, u_{n}-u\right\rangle \\
& =B\left(u_{n}, u_{n}, u_{n}-u\right)-B\left(u_{n}, u_{n+1}, u_{n}-u\right) . \\
& =B\left(u_{n}, u_{n}-u_{n+1}, u_{n}-u\right) \leqq c_{1}\left\|u_{n}-u_{n+1}\right\|\left\|u_{n}-u\right\| .
\end{aligned}
$$

This yields the estimate

$$
\left\|u_{n}-u\right\| \leqq-\frac{c_{1}}{c_{3}}\left\|u_{n}--u_{n+1}\right\|
$$

From (3.7) we see that $0 \leqq \frac{1}{2} c_{2}\left\|u_{n}-\dot{u_{n+1}}\right\|^{2} \leqq C\left(u_{n}\right)-C\left(u_{n+1}\right)$. Since $C$ is bounded from below, necessarily $C\left(u_{n}\right)-C\left(u_{n+1}\right) \rightarrow 0$ for $n \rightarrow+\infty$ and hence, $u_{n}-u_{n+1} \rightarrow 0$. From this and (3.14) we get $u_{n} \rightarrow u$, if $n \rightarrow+\infty$

Remark 3.15: If the functionals $\Phi$ and $B$ have the properties (3.1)-(3.4) (the condition (3.13) need not be satisfied in general) and $C$ is bounded from below, then in virtue of (3.7), for $u_{n+1}=w\left(u_{n}\right), u_{0} \in V$, we have $\psi\left(u_{n}\right)=C\left(u_{n}\right)-C\left(u_{n+1}\right) \rightarrow 0$ and $u_{n}-u_{n+1} \rightarrow 0$, if $n \rightarrow+\infty$.

Example 3.16 (application to the potential compressible flow): Let us consider the functional $\Phi$ defined by $(2.10)$ and (2.11), where the function $\varrho$ satisfies $(1.19)-(1.23)$. We put

$$
\langle f, v\rangle=\int_{\partial \Omega} g v d s, \quad v \in V
$$

and define the form $B$ by the relation.

$$
B(u, v, w)=\int_{\Omega} \varrho\left(|\nabla u|^{2}\right) \nabla v \cdot \nabla w d x, \quad \forall u, v, w \in V
$$

It is easy to see that $B$ is bilinear and symmetric with respect to $v$ and $w$ and that the conditions (3.1)-(3.3) are satisfied (concerning (3.3). - see Lemma 3.21). Let us verify (3.4). This condition can be written in the form

$$
\int_{\Omega}\left[\varrho\left(|\nabla u|^{2}\right) \cdot\left(|\nabla v|^{2}-|\nabla u|^{2}\right)-R\left(|\nabla v|^{2}\right)+R\left(|\nabla u|^{2}\right)\right] d x \geqq 0
$$

for arbitrary $u, v \in V$. It will do to show that

$$
\varrho(\alpha)(\beta-\alpha)-R(\beta)+R(\alpha) \geqq 0, \quad \forall \alpha, \beta \in[0,+\infty) .
$$

In view of the relation $R^{\prime}(s)=\varrho(s)$ in $[0,+-\infty),(3.20)$ is satisfied if and only if the function $R$ is concave. However, this is true, since $R^{\prime \prime}(s)=\varrho^{\prime}(s) \leqq 0$ in $[0,+\infty)$ (cf. (1.23)). It is evident that the equation $(2.9, \mathrm{~b})$ can be written in the form $B(u, u, v)$ $=\langle f, v\rangle$ for all $v \in V$.

In the following we shall deal with some properties of $\Phi, C$ and $B$ from the above example and of the corresponding functional $\psi$ defined by (2.13).

Lemma 3.21: 1. The functional $C(u)=\Phi(u)-\langle f, u\rangle$ is bounded on every bounded set in $V$.

2. $\|w(u)\| \leqq c_{2}^{-1}\|f\|_{v}, \quad \forall u \in V$.

3. $\Phi(u) \geqq \frac{1}{2} \varrho_{\infty}\|u\|^{2}, \quad \forall u \in V$.

4. $|C(w(u))| \leqq c_{4}=$ const, $\cdot \forall u \in V$. 
5. The functional $C$. is coercive $(i . e . ' C(u) \rightarrow+\infty$, if $u \in V$ and $\|u\| \rightarrow+\infty)$, Lipschitz-continuous and bounded from below.

6. The mapping " $u \in V \rightarrow w(u) \in V$ " is continuous.

7. The functional $\psi$ is coercive, continuous and $\psi(u) \geqq 0$ for all $u \in V$.

8. $\Phi$ and $C$ have the Gateaux differentials

and

$$
D^{\prime} \Phi(u, v)=\int_{\Omega} \varrho\left(|\nabla u|^{2}\right) \nabla u \cdot \nabla v d x=B(u, u, v)
$$

$$
\begin{aligned}
D C(u, v) & =\int_{\Omega} \varrho\left(|\nabla u|^{2}\right) \nabla u \cdot \nabla v d x-\int_{\partial \Omega} g v d s \\
& =B(u, u, v)-\langle f, v\rangle, \quad u, v \in V .
\end{aligned}
$$

Proof: 1 . We have

$$
|C(u)|=|\Phi(u)-\langle f, u\rangle| \leqq \frac{1}{2}\left|\int_{\Omega} R\left(|\nabla u|^{2}\right) d x\right|+\|f\|_{v^{*}\|u\|} .
$$

From (1.21) and (2.10), we have $\varrho_{\infty} s \leqq|R(s)| \leqq \varrho_{0} s$ in $[0,+\infty)$ and thus, $\mid C(u)$ $\leqq \frac{1}{2} \varrho_{0}\|u\|^{2}+\|f\|_{v *}\|u\|$.

2. This assertion is an immediate consequence of (3.2) and (3.5):

$$
c_{2}\|\dot{w}(u)\|^{2} \leqq B(u ; w(u), w(u))=\langle f, w(u)\rangle \leqq\|f\|_{v *\|w(u)\| .}
$$

3. Similarly as in the assertion 1 we have

$$
\Phi(u)=\frac{1}{2} \int_{\Omega} R\left(|\nabla u|^{2}\right) d x \geqq \frac{1}{2} \varrho_{\infty}\|u\|^{2} .
$$

4. This is a consequence of assertion 1 and 2 .

5. We have

$$
C(u)=\Phi(u)-\langle f, u\rangle \geqq \frac{1}{2} \varrho_{\infty}\|u\|^{2}-\|f\|_{v} \cdot\|u\| \rightarrow+\infty,
$$

if $\|u\| \rightarrow+\infty$. This and assertion 1 imply the boundedness from below of $C$ From the definition of $\Phi$ and $C$ and the properties of $\varrho$ it follows that both $\Phi$ and $C$ are Lipschitz-continuous.

6. The continuity of $w(u)$ is a consequence of results contained in [27: Ch, 3, $\$$ ] ]. If $u_{n} \rightarrow u$ in $V$, then $\varrho\left(\left|\nabla u_{n}\right|^{2}\right) \rightarrow \varrho\left(|\nabla u|^{2}\right)$ in measure (in $\Omega$ ). Moreover, the functions $\varrho\left(\left|\nabla u_{n}\right|^{2}\right)$ are uniformly bounded in $\Omega$. The functions $w(u)$ or $w\left(u_{n}\right)$ are the solutions of the problems (3.5), where we put $u:=u$ or $u:=u_{n}$, respectively. I.e.,

$$
\int_{\Omega} \varrho\left(|\nabla u|^{2}\right) \nabla w(u) \cdot \nabla v d x=\langle f, v\rangle \quad \forall v \in V_{i}
$$

and

$$
\int_{\Omega} \varrho\left(\left|\nabla u_{n}\right|^{2}\right\rangle \nabla w\left(u_{n}\right) \cdot \dot{\nabla} v d x=\langle f, v\rangle \quad \forall v \in V
$$

Now, by the direct application of $[27: \mathrm{Ch} .3, \S 6]$ we get the convergence $w\left(u_{n}\right) \rightarrow v(u)$ in $V$.

-7. This assertion follows from the assertions $4-6$ and (3.7).

8. This assertion is based on a simple calculation. We leave it to the reader 
Thèrem 3.22: Under the assumption and notation from Example 3.16 it holds:

1. There exists a minimizing sequence of the functional $\psi$.

2. Every minimizing sequence $\left\{u_{n}\right\}_{n=0}^{+\infty}$ of $\psi$ is bounded, $\left\|u_{n}-w\left(u_{n}\right)\right\| \rightarrow 0$, if $n \rightarrow+\infty$, and $\left\{u_{n}\right\}_{n=0}^{\infty}$ is generic, i.e.

$$
B\left(u_{n}, u_{n}, v\right)=\langle f, v\rangle+\left\langle F_{p}, v\right\rangle \quad \forall v \in V,
$$

where $F_{n} \in V^{*}$ and $\left\|F_{n}\right\|_{V^{*}} \rightarrow 0$ for $n \rightarrow+\infty$.

Proof: 1 . As an example of the minimizing sequence to $\psi$ we can use the sequence. $\left\{u_{n}\right\}_{n=0}^{+\infty}$ defined by the iterative process $u_{n+1}=w\left(u_{n}\right)$ with an arbitrary $u_{0} \in V$. In Remark 3.15 we have already shown that $\psi\left(u_{n}\right) \rightarrow 0$, if $n \rightarrow+\infty$. It means that $\left(u_{n}, \rightarrow \inf _{u \in V} \psi(u)=0\right.$, since $\psi \geqq 0$.

2. Let $u_{n} \in V$, .

$$
\lim _{n \rightarrow+\infty} \psi\left(u_{n}\right)=\inf _{u \in V} \psi(u)=0 .
$$

Then there exists $n_{0}$ such that

$$
\frac{1}{2} c_{2}\left\|u_{n}-w\left(u_{n}\right)\right\|^{2} \leqq \psi\left(u_{n}\right) \leqq 1 \quad \forall n \geqq \dot{n}_{0}
$$

Since the sequence $\left\{w\left(u_{n}\right)\right\}_{n=0}^{+\infty}$ is bounded (cf. Lemma 3.21), the sequence $\left\{u_{n}\right\}_{n=0}^{+\infty}$ has the same property. From (3.24) and (3.25) we see that $\left\|u_{n}-w\left(u_{n}\right)\right\| \rightarrow 0$ for $n \rightarrow+\infty$.

Further, in view of (3.5),

$$
B\left(u_{n}, w\left(u_{n}\right), v\right)=\langle f, v\rangle \quad \cdot \dot{\forall} v \in V .
$$

Let us define $F_{. n} \in V^{*}$ by the relation

$$
\left\langle F_{n}, v\right\rangle=B\left(u_{n}, u_{n}-w\left(u_{n}\right), v\right), \quad v \in V .
$$

By this and (3.1), $\left|\left\langle F_{n}, v\right\rangle\right| \leqq c_{1} \mid\left\|u_{n}-w\left(u_{n}\right)\right\|\|v\|$ and hence, $\left\|F_{n}\right\|_{V_{*}} \leqq c_{1}\left\|u_{n}-w\left(u_{n}\right)\right\|$ $\rightarrow 0$, if $n \rightarrow+\infty$. Now it is evident that (3.23) holds

Remark 3.27: Now it is already clear why we have chosen in Section 2 the functional $\psi$ as the cost function of our optimal control problem. The main results are following:

1. $\psi(u) \geqq 0$ for all $u \in V$.

2. inf $\psi(u)=0$.

3. If we find a minimum point $u \epsilon^{\prime} V$ of $\psi$, then $u$ is a solution of the transonic flow problem $(2.9, a-b)$.

In other optimal control methods mentioned in Introduction we meet a somewhat different situation: if we minimize the cost function considered (e.g. $\|u-w(u)\|^{2}$.), then the minimum point need not be a solution of the transonic flow problem, unless we get the zero value of the cost function at this point.

Remark 3.28: In Theorem 3.12 we have shwon that the boundary value problem $(2.9, a-b)$ (which is equivalent to finding a critical point of the functional $C(u)$ $=\Phi(u)-\langle f, u\rangle)$ has a unique solution under the condition (3.13). This condition is valid, if

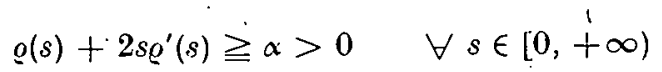

with some $\alpha$. Really, if we denote

$$
g(t)=\varrho\left(|\xi+t \eta|^{2}\right)(\xi+t \eta) \cdot \grave{\eta}
$$


for $\xi, \eta \in \mathbf{R}_{n}$ and $\iota \in[0,1]$, then in view of $(3.29)$ and the condition $\varrho^{\prime} \leqq 0$ (under the notation $\bar{\xi}=\xi+t \eta$ ), we have

$$
\begin{aligned}
g^{\prime}(t) & =\varrho\left(|\xi+t \eta|^{2}\right)|\eta|^{2}+2 \varrho^{\prime}\left(|\xi+t \eta|^{2}\right)[(\xi+t \eta) \cdot \eta]^{2} \\
& =\varrho\left(|\bar{\xi}|^{2}\right)|\eta|^{2}+2 \varrho^{\prime}\left(|\bar{\xi}|^{2}\right)\left(\sum_{i=1}^{n} \tilde{\xi}_{i}^{2} \eta_{i}{ }^{2}+\sum_{\substack{i, j=1 \\
i \neq j}}^{n} \bar{\xi}_{i} \tilde{\xi}_{j} \eta_{i} \eta_{j}\right) \\
& =\varrho\left(|\tilde{\xi}|^{2}\right)|\eta|^{2}+2 \varrho^{\prime}\left(|\bar{\xi}|^{2}\right)\left[|\bar{\xi}|^{2}|\eta|^{2}-\sum_{i \neq j}\left(\bar{\xi}_{i} \eta_{j}-\bar{\xi}_{j} \eta_{i}\right)^{2}\right] \geqq \alpha|\eta|^{2}
\end{aligned}
$$

Hence,

$$
\begin{aligned}
& {\left[\varrho\left(|\xi+\eta|^{2}\right)(\xi+\eta)-\varrho\left(|\xi|^{2}\right) \xi\right] \eta=g(1)-g(0)} \\
& =\int_{0}^{1} g^{\prime}(t) d t \geqq \alpha|\eta|^{2} .
\end{aligned}
$$

Since

$$
D \Phi(u, h)=\int_{\Omega} \underline{Q}\left(|\nabla u|^{2}\right) \nabla u \cdot \nabla h d x
$$

we prove (3.13) , (with $c_{3}=\alpha$ ) by putting $\xi=\nabla u(x), \eta=\nabla h(x)^{\prime}$ (for almost every $x \in \Omega$ ) and by integrating the inequality (3.30) over $\Omega$. (Let us notice that if the condition $\varrho^{\prime} \geqq 0$ were satisfied, then $\cdot g^{\prime}(t) \geqq \varrho\left(|\xi+t \eta|^{2}\right)|\eta|^{2} \geqq \varrho_{\infty}|\eta|^{2}$.)

However, from the construction of the function $\varrho$ and its extension on the interval $[0,+\infty)$ it follows that (3.29) is satisfied for $s \in\left[0, s^{* *}\right]$ with a fixed $s^{* *} \in\left(0, \frac{2 a_{0}{ }^{2}}{\varkappa+1}\right)$ $\left(s^{* *}\right.$ can be chosen arbitrarily close to $\left.\frac{2 a_{0}{ }^{2}}{x+1}\right)$. It means that the condition $(3.13)$ is satisfied on the subset of the space $V$, formed by the velocity potentials corresponding to strictly subsonic flow fields. If we are interested in the subsonic flow only, we can apply the secant modulus method directly in the following way. We choose the constant $s^{* *} \in\left(0, \frac{2 a_{0}{ }^{2}}{x+1}\right)$ and consider the function $\tilde{\varrho}:[0,+\infty) \rightarrow \mathbf{R}_{1}$, which is given by the relation $\tilde{\varrho}(s)=\varrho_{0}\left(1-\frac{x-1}{2 a_{0}{ }^{2}} s\right)^{\frac{1}{x-1}}$ in the interval. $\left[0, s^{* *}\right]$ and satis. fies the conditions (1.19), (1.21)-(1.23) and (3.29). As an easy exercise the following subsonic theorem can be proved.

Theorem 3.31: Let $\varrho: \doteq \bar{\varrho}$, where $\bar{Q}$ is defined above. Then there exists a inique minimum point $u$ of the functional $C(u)=\Phi(u)-\left\langle f^{\prime} u\right\rangle$. This $u$ is the unique solution of the problem $(2.9, \mathrm{a}-\mathrm{b})$ and the secant modulus method converges to it. If $|\nabla u|^{2} \leqq s^{* *}$ in $\Omega$, then $u$ is the velocity potential of a physically admissible irrotational, subsonic, isentropic flow.

The Proof is an immediate application of Theorem 3.12

Let us remark that the solution $u$ from the preceding theorem which does not satisfy the condition $|\nabla u|^{2} \leqq s^{* *}$ has no sense from the physical point of view. Similar access to the study of subsonic flows was applied by FeIstauer in [9-13] with the use of the stream function.

Now let us go back to the transonic flow problem, when the density $\varrho$ has the properties (1.19)-(1.23). Let us prove the second subsonic theorem useful in applications. 

that

Theorem 3.32: Let $\left\{u_{n}\right\}_{n=0}^{+\infty}$ be a minimizing sequence of the functional $C$ or $\psi$ such

$$
\left|\nabla u_{n}\right|^{2} \leqq s^{* *}<\frac{2 a_{0}^{2}}{*+1} \text { in } \Omega \text { for all } n=0,1, \ldots
$$

Then $u_{n} \rightarrow u$ in $V$ and $u$ is the unique solution of the problem $(2.9, a-b)$ in the set $\Subset=\left\{v \in V:|\nabla v|^{2} \leqq s^{* *}\right.$ in $\left.\Omega\right\}$ of strictly subsonic velocity potentials.

Proof: First, let us assume that $\left\{u_{n}\right\}_{n=0}^{+\infty}$ is a minimizing sequence of $\psi$. In view of 'Theorem $3.22,\left\{u_{n}\right\}_{n=0}^{+\infty}$ is bounded. Hence, we can assume that $u_{n} \rightarrow u$ (weakly), if $n \rightarrow+\infty$. By (3.23),

$$
\begin{aligned}
& B\left(u_{n}, u_{n}, u_{n}-u\right)-B\left(u, u, u_{n}-u\right) \\
& =\left\langle f, u_{n}-u\right\rangle+\left\langle F_{n}, u_{n}-u\right\rangle-B\left(u, u, u_{n}-u\right) \rightarrow 0
\end{aligned}
$$

for $n \rightarrow+\infty$, since $\left\|F_{n}\right\|_{V} \bullet \rightarrow,\left\{u_{n}-u\right\}_{n-0}^{\infty}$ is a bounded sequence and the mapping " $v \in \dot{V} \rightarrow B(u, u, v)$ " is a continuous lincar functional on $V$. Further, if we realize that the set $\Subset$ is closed and convex, which implies that $\Subset$ is weakly closed, we conclude that $u \in \Xi$.

The function $\varrho$ satisfies the condition

$$
\varrho(s)+2 s \varrho^{\prime}(s) \geqq \alpha>0 \quad \forall s \in\left[0, s^{* *}\right] .
$$

This implies the existence of such $c_{3}>0$ that

$$
\begin{aligned}
& c_{3}\left\|u_{n}-u\right\|^{2} \\
& \leqq \int_{\Omega}\left[\varrho\left(\left|\nabla u_{n}\right|^{2}\right) \nabla u_{n}-\varrho\left(|\nabla u|^{2}\right) \nabla u\right] \cdot \nabla\left(u_{n}-u\right) d x \\
& =B\left(u_{n}, u_{n}, u_{n}-u\right)-B\left(u, u, u_{n}-u\right) .
\end{aligned}
$$

Now, by using (3.34), we see that $u_{n} \rightarrow u$ (strongly) in $V$, if $n \rightarrow+\infty$. From (3.7) and $\psi\left(u_{n}\right) \rightarrow 0$, if $n \rightarrow+\infty$, we see that $w\left(u_{n}\right) \rightarrow u$. Since $w(u)$. is continuous -(see Lemma 3.21), we have $u=w(u)$, which means' that $u$ is a solution of the problem $(2.9, a-b)$.

If $\left\{u_{n}\right\}_{n=0}^{+\infty}$ is a minimizing sequence of the functional $C$, then we can use the known results from the convex analysis (cf. e.g. [15] or [33]). Again, we can assume that $u_{n} \rightarrow u$ (weakly), if $n \rightarrow-f_{j} \infty$. By (3.35),

$$
D C(u, u-v)-D C(v, u-v) \geqq c_{3}\|u-v\|^{2}, \quad \cdot u, v \in \Subset ;
$$

with $c_{3}>0$ independent of $u, v$. This implies that $C$ is weakly lower semicontinuous in $\subseteq$ and thus,

$$
C(u)=\inf _{n \in G} C(n) \doteq \inf _{n \in V} \dot{C}(n)=\lim _{n \rightarrow+\infty} C\left(u_{n}\right) .
$$

If we use the mean value theorem, and the relation $D C\left(u, u_{n}-u\right)=0$, then we get

$$
\begin{aligned}
0 & \leqq \frac{c_{3}}{2}\left\|u_{n}-u\right\|^{2} \\
& \leqq \int_{0}^{1}\left[D C\left(u+t\left(u_{n}-u\right), u_{n}-u\right)-D C\left(u, u_{n}-u\right)\right] d t \\
& =C\left(u_{n}\right)-C(u) \rightarrow 0,
\end{aligned}
$$

if $n \rightarrow+\infty$ and thus, $u_{n} \rightarrow u$ (strongly). 
Finally, if $u_{1}, u_{2} \in \mathcal{S}$ are two subsonic solutions of the problem $(2.9, \mathrm{a}-\mathrm{b})$, then on the basis of the relation $D C(u, h)=B(u, u, h)-\langle f, h\rangle$ and (3.37) we get the inequality

$$
c_{3}\left\|u_{1}-u_{2}\right\|^{2} \leqq B\left(u_{1}, u_{1}, u_{1}-u_{2}\right)-B\left(u_{2}, u_{2}, u_{1}-u_{2}\right)=0 .
$$

Hence, $u_{1}=u_{2}$ 】

\section{Differantials of $w(u)$ and the existence of a solution to the transonic flow problem} under a posteriori estimates on a minimizing sequence

Theorem 4.1: The mapping : $u \in V \rightarrow w(u) \in \dot{V} "$, defined by (3.5), has the derivative

$$
D \dot{w}(\dot{u}, h)=\left.\frac{d}{d t} w(u+t h)\right|_{t=0}
$$

at every point $u \in V$ and in every direction $h \in V \cap W^{1 \infty}(\Omega)$. The mapping " $h \rightarrow D w$ $\times(u, h)^{\prime \prime}$ is linear for each $u \in V$ and uniformly bounded with respect to $u \in V$. For every $h \in V \cap W^{1, \infty}(\Omega)$ " $u \rightarrow \operatorname{Du}(u, h)$ " is continuous mapping of $V$ into $V$. Hence, Dw $(w, \cdot)$ is the Gîteaux differential of $w(u)$.

Proof: For $u \in V$ and $h \in V \cap W^{1, \infty}(\Omega)$ we denote $u_{t}=u+t h, w_{t} \doteq w\left(u_{t}\right)$, $w_{t}=\left(w_{\ell}-w_{0}\right) / t$ and $w=w_{0}=w(u)$. It holds

$$
\begin{aligned}
0 & =\frac{1}{t}\left[B\left(u_{t}, w_{t}, v\right)-B\left(u_{0}, w_{0}, v\right)\right] \\
= & \frac{1}{t} \int_{\Omega}\left\{\left[\varrho\left(\left|\nabla u_{t}\right|^{2}\right)-\varrho\left(\left|\nabla u_{0}\right|^{2}\right)\right] \nabla w_{t} ;\right. \\
& \left.+\varrho\left(\left|\nabla u_{0}\right|^{2}\right)\left(\nabla w_{t}-\nabla w_{0}\right)\right\} \cdot \nabla v d x, \quad v \in V .
\end{aligned}
$$

If we use the mean value theorem, then

$$
\begin{aligned}
& \int_{\Omega} \varrho\left(|\nabla u|^{2}\right) \nabla \omega_{l} \cdot \nabla v d x \\
& =-2 \int_{\Omega}\left(\int_{0}^{1} \varrho^{\prime}\left(\left|\nabla u_{t \mathrm{r}}\right|^{2}\right)\left(\nabla u_{t \mathrm{r}} \cdot \nabla h\right) d \tau\right)\left(\nabla w_{t} \cdot \nabla v\right) d x .
\end{aligned}
$$

From this, for $t \rightarrow 0$, we get

$$
\begin{aligned}
& \int_{\Omega} \varrho\left(|\nabla u|^{2}\right) \nabla D i v(u, h) \cdot \nabla v d x \\
& =-2 \int_{\Omega} \varrho^{\prime}\left(|\nabla u|^{2}\right)(\nabla u \cdot \nabla h)(\nabla w: \nabla v) d x, \quad v \in V .
\end{aligned}
$$

In view of the assumption $h \in V \cap W^{1, \infty}(\Omega)$ and the properties of $\varrho$, the right-hand side in (4.5) (considered as a function of $v \in V$ ) defines a continuous linear functional $F^{\prime}(u, w, h)$ on $V$. Hence, (4.5) which can be written in the form

$$
B(u, D w(u, h), v)=\langle F(\dot{u}, w, \dot{h}), v\rangle, \quad v \in V,
$$

has a unique solution $D w(u, h) \in V$. From the continuous dependence of $w$ on $u$, the continuity of $F$ with respect to $u, w, h$ and the results from [27:Ch. 3, \$ 6] all remaining assertions of Theorem 4.1 follow 
Remark 4.7: Similarly, supposing that $\varrho^{\prime \prime}$ is continuous in $[0,+\infty)$ and that the estimate $\left|\varrho^{\prime \prime}(s)(1+s)\right| \leqq c_{5}=$ const holds in $[0,+\infty)$, we can prove the existence of the second differential $D^{2} w(u, h, k)$ for $u \in V$ and $h, k \in V \cap W^{1, \infty}(\Omega)$ and the relation $(w=w(u))$

$$
\begin{aligned}
& \int_{\Omega} \varrho\left(|\nabla u|^{2}\right) \nabla D^{2} w(u, h, k) \cdot \nabla v d x \\
& =-2 \int_{\Omega} \varrho^{\prime}\left(|\nabla u|^{2}\right)(\nabla u \cdot \nabla k)(\nabla D w(u, h) \cdot \nabla v) d x \\
& \quad-4 \int_{\Omega} \varrho^{\prime \prime}\left(|\nabla u|^{2}\right)(\nabla u \cdot \nabla h)(\nabla u \cdot \nabla k)(\nabla w \cdot \nabla v) d x \\
& -2 \int_{\Omega} \varrho^{\prime \prime}\left(|\nabla u|^{2}\right)(\nabla h \cdot \nabla k)(\nabla w \cdot \nabla v) d x \\
& -2 \int_{\Omega} \varrho^{\prime}\left(|\nabla u|^{2}\right)(\nabla u \cdot \nabla h) \cdot(\nabla D w(u, k) \cdot \nabla v) d x
\end{aligned}
$$

Lemma 4.9: The functional $\psi$ is differentiable in the space $V$ with respect to any direction $h \in V \cap W^{1, \infty}(\Omega)$. The differential $D \psi(u, h)$ has the form

$$
\begin{aligned}
D \psi(u, h)= & \int_{\Omega} \varrho\left(|\nabla u|^{2}\right) \nabla_{!} u \cdot \nabla h d x \\
& -\int_{\partial \Omega} g h d s-\int_{\Omega} \varrho\left(|\nabla w(u)|^{2}\right) \nabla w(u) \cdot \nabla D w(u, h) d x \\
& +\int_{\partial \Omega} g D w(u, h) d s, \quad u \in V, h \in V \cap W^{1, \infty}(\Omega) .
\end{aligned}
$$

The Propof follows from the definition (2.13) of $\psi$ and from Lemma 3.21

The following theorem is devoted to the uniqueness of the solution to the problem $(2.9, \mathrm{a}-\mathrm{b})$.

Theorem 4.11: Let the condition

$$
\int_{\partial \Omega} g[D w(u, u-v)-D w(v, u-v)] d s \leqq 0
$$

hold for all $u, v \in V$ satisfying (1.24), i.e.

$$
-|\nabla u|^{2},|\nabla v|^{2} \leqq s_{1}<\frac{6 a_{0}^{2}}{x+1}
$$

Then the problem $(2.9, \mathrm{a}-\mathrm{b})$ has' at most one solution in the class of velocity potentials $u \in V$.satisfying (4.13).

Proof: Let $u, v$ be two such solutions. Then $\dot{\psi}(u)=\psi(v)=\inf _{\xi \in V} \varphi(\xi)=0$ and thus, in view of Lemma 4.9,

$$
\begin{aligned}
0= & D \psi(u, u-v) \\
= & \int_{\Omega} \varrho\left(|\nabla \dot{w}|^{2}\right) \nabla u \cdot \nabla(u-v) d x-\int_{\partial \Omega} g(u-v) d s \\
& \quad-\int_{\Omega} \varrho\left(|\nabla w(u)|^{2}\right) \nabla w(u) \cdot \nabla D \dot{w}(u, u-v) d x+\int_{\partial \Omega} g D w(u, u-v) d s
\end{aligned}
$$


and .

$$
\begin{aligned}
0= & D \psi(v, u-v)=\int_{\Omega} \varrho\left(|\nabla v|^{2}\right) \nabla v \cdot \nabla(u-v) d x-\int_{\partial \Omega} g(u-v) d s \\
& -\int_{Q} \varrho\left(|\nabla w(v)|^{2}\right) \nabla w(v) \cdot \nabla D w(v, u-v) d x+\int_{\partial \Omega} g D w(v, u-v) d s .
\end{aligned}
$$

The functions $u, v$ as the solutions of the problem $(2.9, \mathrm{a}-\mathrm{b})$ satisfy the relations

$$
\begin{aligned}
& \int_{\Omega} \grave{\grave{e}}\left(|\nabla u|^{2}\right) \cdot \nabla u \cdot \nabla(u-v) d x=\int_{\partial \Omega} g(u-v) d s, \\
& \int_{\Omega} \varrho\left(|\nabla v|^{2}\right) \nabla v \cdot \nabla(u-v) d x=\int_{\partial \Omega} g(u-v) d s .
\end{aligned}
$$

If we subtract (4.15) from (4.14) and take into accounit (4.5), (4.12), (4.16, a-b) and the fact that $u=w(u), v=w(v)$, we get

$$
\begin{gathered}
0=\int_{\partial \Omega} g[D w(u, u-v)-D w(v, u-v)] d s \\
\left.\quad-\int_{\Omega} \varrho\left(|\nabla u|^{2}\right) \nabla u: \nabla D w(u, u-v)\right] d x \\
\left.\quad+\int_{\Omega} \varrho\left(|\nabla v|^{2}\right) \nabla v \cdot \nabla D \dot{u}(v, u-v)\right] d x \\
\leqq \\
\quad 2 \int_{\Omega} \varrho^{\prime}\left(|\nabla u|^{2}\right)|\nabla u|^{2}(\nabla u \cdot \nabla(u-v)) d x \\
\quad-2 \int_{\Omega} \varrho^{\prime}\left(|\nabla v|^{2}\right)|\nabla v|^{2}(\nabla v \cdot \nabla(u-v)) d x
\end{gathered}
$$

Now; let us multiply (4.17) by $\lambda / 2<.0$ and add the difference $(4.16, \mathrm{a})-(4.16, \mathrm{~b})$ :

$$
\begin{aligned}
& 0 \geqq \int_{\Omega}\left\{\left[\left(|\nabla u|^{2}\right)+\lambda \varrho^{\prime}\left(|\nabla u|^{2}\right)|\nabla u|^{2}\right] \nabla u\right. \\
& \left.-\left[\varrho\left(|\nabla v|^{2}\right)+\ddot{\lambda} \varrho^{\prime}\left(|\nabla v|^{2}\right)|\nabla v|^{2}\right] \nabla v\right\} \cdot \nabla(u-v) d x \\
& =\int_{\Omega}\left[h\left(|\nabla u|^{2}\right) \dot{\nabla} u-h\left(|\nabla v|^{2}\right) \nabla v\right] \cdot \nabla(u-v) d x,
\end{aligned}
$$

where $h(s)=\varrho(s)+\lambda \cdot s \varrho^{\prime}(s)$ : We have

$$
\begin{aligned}
h(s)+2 s h^{\prime}(s) & =\varrho(s)+(3 \hat{\lambda}+2) s \varrho^{\prime}(s)+2 \lambda s^{2} \varrho^{\prime \prime}(s) \\
& =\varrho(s)+2 s \varrho^{\prime}(s)-\lambda\left[-3 s \varrho_{0}^{\prime}(s)-2 s^{2} \varrho^{\prime \prime}(s)\right] .
\end{aligned}
$$

After some calculation "we find out that $-3 s \varrho^{\prime}(s)-2 s^{2} \varrho^{\prime \prime}(s) \geqq \alpha_{1} s$ for $s \in\left[0, s_{1}\right]$ with $\alpha_{1}>0$. For $0 \leqq s \leqq s^{* *}<\frac{2 a_{0}{ }^{2}}{x+1}$ we have $\varrho(s)+2 s \varrho^{\prime}(s) \geqq \alpha>0$ and thus, $h(s)+2 s h^{\prime}(s) \geqq \alpha$. If $s \geqq s^{* *}$ and $\lambda$ is close to $-\dot{\infty}$, then $h(s)+2 s h^{\prime}(s) \geqq \tilde{\alpha}>0$. Hence, wa see that there exist $\lambda<0$ and $\beta>0$ such tliat.

$$
h(s)+2 s h^{\prime}(s) \geqq \beta>0 \quad \forall s \in\left[0, s_{1}\right] .
$$

Now we proceed similarly as in Remark 3.28. For $t \in[0,1], \xi, \bar{\xi} \in \mathbf{R}_{n},|\xi|^{2},|\bar{\xi}|^{2} \leqq s_{1}$ - and $\eta=\bar{\xi}-\xi$ we put

$$
\begin{aligned}
& g(t)=h\left(|\xi+t \eta|^{2}\right)(\xi+i \eta) \cdot \eta \\
& =\left\lfloor\varrho\left(|\xi,+t \eta|^{2}\right)+i \varrho^{\prime}\left(|\xi+t \eta|^{2}\right)|\dot{\xi}+t \eta|^{2}\right](\xi+t \eta) \therefore \eta .
\end{aligned}
$$


Then, in view of (4.19) and the evident inequality $h \geqq \varrho_{\infty}$, we have

and

$$
\begin{aligned}
& g^{\prime}(t)=h\left(|\xi+t \eta|^{2}\right)|\eta|^{2}+2 h^{\prime}\left(|\xi+t \eta|^{2}\right)[(\xi+t \eta): \eta]^{2} \geqq \beta_{1}|\eta|^{2} \\
& \beta_{1}=\min \left(\beta, \varrho_{\infty}\right)>0
\end{aligned}
$$

$$
g(1)-g(0)=\int_{0}^{1} g^{\prime}(t) d t \geqq \beta_{1}^{\prime}|\eta|^{2}
$$

Finally, if we denote $\xi \stackrel{=}{=} v(x), \xi=\dot{\nabla} u(x)$ (for almost every $x \in \Omega$ ), then by (4.20) we easily find out that

$$
\begin{aligned}
& \int_{\Omega}\left[h\left(|\nabla u|^{2}\right) \nabla u-h\left(|\nabla v|^{2}\right) \nabla v\right] \cdot \nabla(u-v) d x \\
& \geqq \dot{\beta}_{1} \int_{\Omega}|\nabla(u-v)|^{2} d x=\beta_{1}\|u-v\|^{2} .
\end{aligned}
$$

In virtue of the inequality (4.18), $\left\|u-{ }^{6} v\right\|^{2}=0$ which yields $u=v$

Theorem 4.11 indicates that the behaviour of the term $\int_{0} g D w(u, h) d s$ will probably play an important role in the study of the transonic flow problem and it will be necessary, to control this term in a suitable way. Let us consider a minimizing sequence $\left\{u_{n}\right\}_{n=0}^{+\infty}$ of the functional $\psi$. Then

$$
\lim _{n \rightarrow+\infty} \sup _{\|h\|_{V\left(W^{1, \infty}(\Omega)\right.}\left|D \psi\left(u_{n}, h\right)\right|=0}
$$

From this, Lemma 4.9 , and the relation

$$
\int_{\Omega} \varrho\left(\left|\nabla u_{n}\right|^{2}\right) \nabla u_{n} \cdot \nabla h d x-\int_{\Omega \Omega} g h d s \rightarrow 0 \text { for } n \rightarrow+\infty
$$

(which follows from Theorem $3: 22$ ), we can see that if $h \in V \cap W^{1, \infty}(\Omega)$ and $\|h\|_{V_{n} W^{1, \infty}(\Omega)} \leqq 1$, thèn.

$$
\begin{aligned}
0 & =\lim _{n \rightarrow+\infty} D \dot{\psi}\left(u_{n}, h\right) \\
& =\lim _{n \rightarrow+\infty}\left[-\int_{\Omega} \varrho\left(\left|\nabla w\left(u_{n}\right)\right|^{2}\right) \nabla w\left(u_{n}\right) \cdot \nabla D w\left(u_{n}, h\right) d x+\int_{\partial \Omega} g D w\left(u_{n}, h\right) d s\right] .
\end{aligned}
$$

Since $u_{n}-w\left(u_{n}\right) \rightarrow 0$ for $n \rightarrow+\infty$ (again by Theorem 3.22), $w\left(u_{n}\right)$ can be approximated by $u_{n}$ for large $n$. This, (4.5) (where we put $u=v=u_{n}$ ) and (4.22) imply that the term $\int_{\partial \Omega} g D w\left(u_{n}, h\right) d s$ can be approximated by

$$
-2 \int_{\Omega} \varrho^{\prime}\left(\left|\nabla u_{n}\right|^{2}\right)\left|\nabla u_{n}\right|^{2} \nabla u_{n} \cdot \dot{\nabla} h d x
$$

Therefore, in the following we shall use the condition (1.17) to control the term $\int_{\Omega} g D v v(u, h) d s$. It is possible to show that this condition has a relation to upwinding the density (used e.g. in $[2, \dot{5}, 7]$ ).

Now we shall prove the theorem on the solvability of the transonic flow problem. The entropy condition (1.17) plays the fundamental role in the proof because of its compactification properties. 
Theorem 4.23 (1st fundamental): Let $\left\{u_{n}\right\}_{n=0}^{+\infty}$ be a minimizing sequence of the functional $\psi$, satisfying a posteriori the condition (4.13) and the entropy condition (1.17) with some $M \in \mathbf{R}_{1}$. Let $u_{n} \rightarrow u$ (weakly) in $V$, if $n \rightarrow+\infty$. Then $\vec{u}_{n} \rightarrow u$ (strongly) in $V$, if $n \rightarrow+\infty$ and $u$ is a solution of the problem $(2.9, \mathrm{a}-\mathrm{b})$, satisfying the condition (4.13).

Proof: Let us consider a sequence $\left\{G_{n}\right\}_{n \rightarrow 0}^{+\infty}$ of functionals defined on $V$ :

$$
\left\langle G_{n}, h\right\rangle=\int_{\Omega} \varrho^{\prime}\left(\left|\nabla u_{n}\right|^{2}\right)\left|\nabla u_{n}\right|^{2} \nabla u_{n} \cdot \nabla h d x, \quad . h \in V .
$$

Without loss of generality we can assume that $G_{n} \rightarrow G$ (weakly), if $n \rightarrow+\infty$. Let us denote the restriction of $\left\langle G_{n}, h\right\rangle$ or $\langle G, h\rangle$ to $W_{0}^{1.2}(\Omega)$ by: $G_{n}(h)$ or $G(h)$, respectively, and put

$$
H_{n}(h)=M \int_{\Omega} h d x-G_{n}(h), \quad H(h)=M \int_{\Omega} h d x-G(h) .
$$

From the condition (1.17) it follows that $H_{n}(h) \geqq 0, \ddot{H}(h) \geqq 0$ for $h \geqq 0$. If we use the result of Murat [26], we get $H_{n} \rightarrow H$ in $\left(W_{0}^{1, p}(\Omega)\right)^{*}$ for each $p>2$. Hence, $G_{n} \rightarrow G$ in $\left(W_{0}^{1, p}(\Omega)\right) *$.

Now, let $h \in V \cap W^{1, \infty}(\Omega)$. Following Agmon, Douglis and NirenBerg [1], we can write

$$
h=h^{1}+h^{2},
$$

where $\triangle h^{1}=0$ and $h^{2} \in W_{0}^{1.2}(\Omega) .(4.26)$ is an orthogonal decomposition of the space $W^{1,2}(\Omega)$ into harmonic functions and functions with zero traces. By MEYers [25]; there exists $p_{1}>2$. such that the mapping " $h \rightarrow h^{i}$ " $(i=1,2)$ is continuous from $W^{1, p_{1}}(\Omega)$ into $W^{1, p_{1}}(\Omega)$. Further, since the imbedding $W^{1, \infty}(\partial \Omega) \subset W^{1-\frac{1}{p_{1}}, p_{1}}(\partial \Omega)$ is

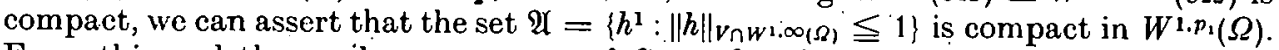
From this and the weak convergence of $G_{n}$ to $G$, it follows that

$$
\therefore \lim _{n \rightarrow+\infty\left\|h^{\prime}\right\|_{V \cap W^{1, \infty}(\Omega)} \leq 1}\left|\left\langle G_{n}-G, h^{1}\right\rangle\right|=0 .
$$

(For proving this, we can use a finite $\varepsilon$-network in the set $\mathfrak{A}$.) Moreover, from $G_{n} \rightarrow G$ in $\left(W_{l^{1}} 0^{1 ; p_{1}}(\Omega)\right)^{*}$ and the properties of the mapping " $h \rightarrow h^{2}$ " it follows that also.

$$
\lim _{n \rightarrow+\infty\|n\|} \sup _{V \cap W 1, \infty(\Omega)}\left|\left\langle G_{n}-G ; h^{2}\right\rangle\right|=0 .
$$

This, (4.26) and (4.27) imply ${ }^{\prime} G_{n}^{\prime} \rightarrow G^{\prime}$ in $\left[V \cap W^{1, \infty}(\Omega)\right]^{*}$.

Similarly as in the proof of Theorem 4.11 , we put $h(s)=\varrho(s)+\lambda s \varrho^{\prime}(s)$ in $\left[0, \frac{6 a_{0}{ }^{2}}{x+1}\right]$ and choose $\lambda$ close to $-\infty$ so that the condition (4.19) is valid. Then, by (4.24) and Theorem 3.22 for $h_{n}=u-\dot{u}_{n}$,

$$
\begin{aligned}
& \int_{\Omega} h\left(\left|\nabla u_{n}\right|^{2}\right) \nabla u_{n} \cdot \nabla h_{n} d x \\
& =\int_{\Omega} \varrho\left(\left|\nabla u_{n}\right|^{2}\right) \nabla u_{n} \cdot \nabla \dot{h}_{n} d x+\lambda \int_{\Omega} \varrho^{\prime}\left(\left|\nabla u_{n}\right|^{2}\right)\left|\nabla u_{n}\right|^{2} \nabla u_{n} \cdot \nabla h_{n} d x \\
& =\int_{\partial \Omega} g h_{n} d s+\left\langle F_{n}, h_{n}\right\rangle+\lambda\left\langle\left\langle G_{n}, h_{n}\right\rangle .\right.
\end{aligned}
$$


From $h_{n} \rightarrow 0$ (weakly) and the properties of $F_{n}$ and $G_{n}$ we get that the expression in (4.28) tends to zero, if $n \rightarrow+\infty$. If we subtract the expression

$$
\int_{\Omega} h\left(|\nabla u|^{2}\right) \nabla u \cdot \nabla h_{n} d x \quad(\rightarrow 0, \text { if } n \rightarrow+\infty)
$$

from (4.28) and use (4.21), where $v:=u_{n}$ and $u-v:=h_{n}$, then, we get

$$
\beta_{1}\left\|h_{n}\right\|^{2} \leqq \int_{\partial \Omega} g \bar{h}_{n} d s+\left\langle F_{n}, h_{n}\right\rangle+\lambda\left\langle G_{n}^{\prime}, h_{n}\right\rangle-\int_{\Omega} h\left(|\nabla u|^{2}\right) \nabla u \cdot \nabla h_{n} d x \rightarrow 0 .
$$

This yields $h_{n} \rightarrow 0$ (if $n \rightarrow+\infty$ ). It means that $u_{n} \rightarrow \dot{u}$ (strongly) and, in view of Theorem 3.22 and the continuity of the mapping $w(u)$, we have $u \doteq v(u)$. Hence, $u$ is a solution of the problem $(2.9, \mathrm{a}-\mathrm{b})$

In the following theorem we shall show that also the entropy condition (1.18), used e.g. in [3, 17, 18,32], has similar compactification properties as (1.17).

. Theorem 4.30 (2nd /undamental): Let us assume that g satisfies the conditions (1.19)-(1.23) and

$$
\left.|g(s)-\alpha| \sqrt{s} \leqq c<+\infty, \quad s \in[0,+\infty)^{1}\right)
$$

with constants $\alpha, c>0$ and let $u$ sis consider the boundary condition (2.4). Let $\left\{u_{n}\right\}_{n=0}^{+\infty}$ be a minimizing sequence of the functional $\psi$, satisfying a posteriori the condition (1.18), and let $u_{n} \rightarrow u$ (weakly) in $V$, if $n \rightarrow-+\infty$. Then $u_{n} \rightarrow u$ (strongly) in $V, u$ is a solution of the problem $(2.9, \mathrm{a}-\mathrm{b})$ and $\left\|u_{n}\right\|_{W^{1, p_{2}(\Omega)}},\|u\|_{W^{1, p_{*}(\Omega)}} \leqq \tilde{c}$ with some $p_{2}>2$ and $\bar{c}>0$.

Proof: By Theorem 3.22,

$$
\int_{\Omega} \varrho\left(\left|\nabla u_{n}\right|^{2}\right\rangle \nabla u_{n} \cdot \nabla v d x=\int_{\partial ?} g v d s-\left\langle F_{n}, v\right\rangle, \quad v \in V,
$$

where $F_{n} \rightarrow 0$ in $V^{*}$. From this we get

$$
\begin{aligned}
\alpha \int_{\Omega} \nabla u_{n}: \nabla v d x= & \int_{\Omega}\left(\alpha-\varrho\left(\left|\nabla u_{n}\right|^{2}\right)\right) \nabla u_{n} \cdot{ }^{\prime} \nabla v d x \\
& +\int_{\Omega} g v d s+\left\langle\cdot\left\langle F_{n}, v\right\rangle, \quad v \in V^{\prime}\right.
\end{aligned}
$$

Let $u_{n}^{1} \in V$ be a solution of the problem

$$
\begin{aligned}
\alpha \int_{\Omega} \nabla u_{n}^{1} \cdot \nabla v d x= & \int_{\Omega}\left(\alpha-\varrho\left(\left|\nabla u_{n}\right|^{2}\right) \nabla \dot{u}_{n} \cdot \nabla v d x\right. \\
& +\int_{\partial \Omega} g v d s \quad \forall v \in V
\end{aligned}
$$

and $u_{n}^{2}, \in V$ be a solution of the problem

$$
\alpha \int_{\Omega} \nabla u_{n}^{2} \cdot \nabla v d x=\left\langle F_{n}, v\right\rangle \quad \forall v \in V
$$

1) This condition is sattisfied e.g., if we extend $\underline{g}$ to $[0,+\infty]$ in such a way that $g(s)=$ const for large $s$ (cf. Section 1). 
Then $u_{n}=u_{n}{ }^{1}+u_{n}{ }^{2}$. It is evident that $u_{n}{ }^{2} \rightarrow 0$ in $V$ (since $\cdot F_{n} \rightarrow 0$ in $V^{*}$ ). Hence, $u_{n}{ }^{1 \cdot} \rightarrow u$.

Now; by [25]

$$
\left\|u_{n}{ }^{1}\right\|_{W^{1, p_{2(\Omega)}}} \leqq \tilde{c}=\mathrm{const} \quad \forall n=0,1, \ldots
$$

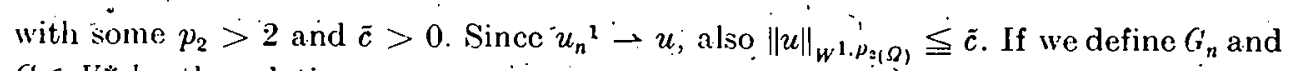
$G \in V^{*}$ by the relations

$$
\left\langle G_{n}, h\right\rangle=\int_{S} \nabla u_{n}, \nabla h d \dot{x}, \quad h \in V
$$

and

$$
\langle G, h\rangle=\int_{\Omega} \nabla u \cdot \nabla h^{\prime} d x, \quad h \in \dot{V}
$$

respectively, then $G_{n} \rightarrow G$. In the following we shall proceed similarly as in the proof of 'Theorem 4.23: First, if we realize that all $u_{n}$ satisfy the condition (1.18); then we see that in view of [26], $G_{n} \rightarrow G$ in $\left(W_{0}^{1 . p}(\Omega)\right)^{*}$ for all $p>2$ : Further, let every $h \in V \cap W^{1, p_{z}}(\Omega)$ be decomposed in the form (4.26). Using again Meyers' results from [25] and considering $p_{1}$ from the proof of 'Theorem 4.23 such that $2<p_{1}<p_{2}$, then in view of the compact imbedding of $W^{1-\frac{1}{p_{2}}, p_{s}}(\partial \Omega)$ into $W^{1-\frac{1}{p_{1}}, p_{1}}(\partial Q)$, we find out that the set $\mathfrak{A}=\left\{h^{1}:\|h\|_{V \cap W^{1, p_{2}(\Omega)}} \leqq 1\right\}$ is compact in $W^{1, p_{1}}(\Omega)$. Now, by the same arguments as in the proof of Theorem 4.23, we conclude that $G_{n} \rightarrow G^{\prime}$ in $\left[V^{-} \cap W^{1, p_{2}}(\Omega)\right]^{*}$.

Let $h_{n}=u_{n}^{1}-u$. Hence, ${ }^{1} h_{n} \dot{\rightarrow} 0$ (weakly). If we use (4.32), (4.33), (4.36), (4.37), then

$$
\begin{aligned}
& \alpha\left\|h_{n}\right\|^{2}=\alpha \int_{\Omega}\left|\nabla h_{n}\right|^{2} d x \\
& =\alpha \int_{\Omega} \nabla u_{n} \cdot \nabla h_{n} d x-\alpha \int_{\Omega} \nabla u \cdot \nabla h_{n} d x+\left\langle F_{n}, h_{n}\right\rangle \\
& =\alpha\left\langle G_{n}-G, h_{n}\right\rangle+\left\langle F_{n}, h_{n}\right\rangle \rightarrow 0
\end{aligned}
$$

and,thus, $u_{n}^{1} \rightarrow u$ in $\dot{V}$. Hence, $u_{n} \rightarrow u$ and $u$ is a solution of the problem $(2.9, \mathrm{a}-\mathrm{b})$

\section{Regularity of the minimizing sequence}

In the light of Theorems 4.23 and 4.30 we come to a,natural question "How regular the minimizing sequence of the functional $\psi$ can be found?" In this section we shall assume that $\partial \Omega$ is smooth and consider the Neumann condition (2.4) on $\partial \Omega$.

Theorem 5.1: Let the conditions (1.19)-(1.23) and (4.31) be sutisfied and let $\left\{u_{n}\right\}_{n=0}^{+\infty}$ be a minimizing sequence of the functional $\psi$. Then, for the decomposition $u_{n}$ $=u_{n}{ }^{1}+u_{n}{ }^{2}$ from the proof of Theorem 4.30 , it holds

$$
\begin{aligned}
& \left\|u_{n}^{2}\right\| \rightarrow 0 \quad(\text { in } V), \\
& \left\|u_{n}{ }^{1}\right\|_{w^{1, p}(\Omega)} \leqq c(p)<+\infty \quad \forall p<+\infty, n=0,1, \ldots
\end{aligned}
$$

and $\left\{u_{n}{ }^{1}\right\}_{n=0}^{+\infty}$ is also a minimizing sequence. 
Proof: The assertion (5.2) has been already proved in Theorem 4.30. With respect to (4.33), the regularity of $\partial \Omega$ and $(4.35)$, we get $(5.3)$ on the basis of $W^{1, p}(\Omega)$ - esti= mates of the solution to (4.33) (cf. [1]).

It remains to show that $\left\{u_{n}^{1}\right\}_{n=0}^{+\infty}$ is also a minimizing sequence of $\psi$. In virtue of the relation $\psi(u)=C(u)-C(w(u))$ and the Lipschitz-continuity of $C$, it is sufficient to prove that $w\left(u_{n}\right)-w\left(u_{n}{ }^{1}\right) \rightarrow 0$ in $-V$, if $n \rightarrow+\infty$. Let us put $w_{n}=w\left(u_{n}\right), w_{n}{ }^{1}$ $=w\left(u_{n}^{1}\right)$. With respect to (3.5) and (3.18) we have

$$
\begin{aligned}
& B\left(u_{n}, w_{n}-w_{n}{ }^{1}, v\right) \\
\cdots & =\int_{\Omega} \varrho\left(\left|\nabla u_{n}\right|^{2}\right)\left(\nabla w_{n}-\nabla w_{n^{1}}^{1}\right) \cdot \nabla v d x \\
= & \int_{\Omega}\left[\varrho\left(\left|\nabla u_{n}^{1}\right|^{2}\right)-\varrho\left(\left|\nabla u_{n}\right|^{2}\right)\right] \nabla w_{n}^{1}: \nabla v d x, \ldots v \in V .
\end{aligned}
$$

If we put $v:=w_{n}-w_{n}{ }^{1}$, use (3.2) and apply the Cauchy.inequality to the right-hand side, then

$$
\begin{aligned}
& c_{2}\left\|w_{n}-w_{n}^{1}\right\|^{2} \\
& \leqq\left\{\int_{0}\left[\varrho\left(\left|\nabla u_{n}^{1}\right|^{2}\right)-\varrho\left(\left|\nabla u_{n}\right|^{2}\right)\right]^{2}\left|\nabla w_{n}^{1}\right|^{2} d x\right\}^{1 / 2}|| w_{n}-w_{n}^{1} \|
\end{aligned}
$$

Hence, it will do to prove that

$$
\int_{\Omega}\left[\varrho\left(\left|\nabla u_{n}^{1}\right|^{2}\right)-\varrho\left(\left|\nabla u_{n}\right|^{2}\right)\right]^{2}\left|\nabla w_{n}^{1}\right|^{2} d x \rightarrow 0
$$

if $n \rightarrow+\infty$.

We can assume that $\nabla u_{n}{ }^{2}(x)^{\prime} \rightarrow 0$ almost every where in $\Omega$. Using again [25], we get $p_{3}>2$ such that'

$$
\|w(u)\|_{w^{1}, p_{z(\Omega)}} \leqq e^{*} \quad \forall \cdot u \in V
$$

Now, let us choose an arbitrary $\varepsilon>0$. Let $\mathfrak{M} \subset \Omega$ be a measurable set. By the Hölder ińequality and (5.7) we get.

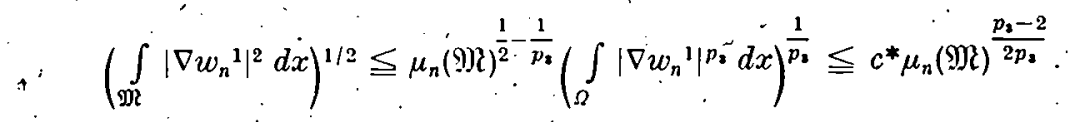

(We denote by $\mu_{n}$ the $n$-dimensional Lebesque measure in $\mathbf{R}_{n}$.) We choose $\mathfrak{M}_{\mathcal{L}} \subseteq \Omega$ with $\left.\mu_{n}(9)\right)<\left(\frac{\varepsilon}{4 c^{*} \varrho_{0}}\right)^{\frac{2 p_{3}}{p_{3}-2}}\left(\underline{o}_{0} \cdot\right.$ is the constant from $\left.(1.21)\right)$ in such a way that in virtue of Jegorov's theorem, $\nabla u_{n}{ }^{2}(x) \rightarrow 0$ uniformly in $\Omega-\mathfrak{M}$. If $\delta>0$, let $n_{0}$ be such that $\left|\nabla u_{n}{ }^{2}(x)\right|<\delta$ in $\Omega-\mathfrak{M}$ for all $n \geqq n_{0}$. Since $\varrho$ is ILipschitz-continuous in $[0,+\infty)$ and $u_{n}=u_{n}{ }^{1}+u_{n}^{2}$, we get (by using the Hölder inequality)

$$
\begin{aligned}
& I(\Omega-\mathfrak{l}):=\left\{\int_{\Omega-\mathfrak{R}}\left[\varrho\left(\left|\nabla u_{n}{ }^{2}\right|^{2}\right)-\varrho\left(\left|\nabla u_{n}\right|^{2}\right)\right]^{2}\left|\nabla w_{n}{ }^{1}\right|^{2} d x\right\}^{1 / 2} \\
& \leqq \text { const } \cdot\left\{\int_{\Omega}\left(\left|\nabla u_{n}^{2}\right|^{2}+2\left|\nabla u_{n}{ }^{1}\right|\left|\nabla u_{n}^{2}\right|\right)^{2}\left|\nabla w_{n}^{1}\right|^{2} d x\right\}^{i / 2} \\
& \leqq \text { const } \cdot\left\{\int_{\Omega-\mathfrak{M}}\left(\delta^{2}+2 \delta\left|\nabla u_{n}^{\mathrm{i}}\right|\right)^{2}\left|\nabla w_{n}^{\mathrm{i}}\right|^{2} d x\right\}^{1 / 2}
\end{aligned}
$$




$$
\begin{aligned}
& \leqq \text { const } \cdot\left\{\delta^{2}\left(\int_{\Omega} \cdot\left|\nabla w_{n}^{1}\right|^{2} d x\right)^{1 / 2}\right. \\
& \left.+\delta\left(\int_{0} \mid \nabla u_{n}{ }^{1} \frac{2 p_{3}}{p_{2}-2} d x\right)^{\frac{p_{3}-2}{2 p_{2}}}\left(\int_{\Omega}\left|\nabla w_{n}{ }^{1}\right|^{p_{2}} d x\right)^{\frac{1}{p_{2}}}\right\}
\end{aligned}
$$

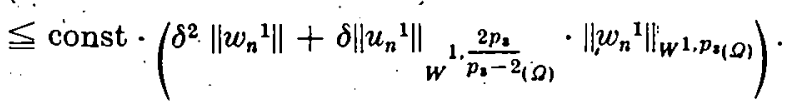

Now, if we use Lemma $3.21,(5.3)$ and $(5.7)$, we see that there exists a constant $c^{* *}$ such that

$$
I(\Omega-\Omega) \zeta) \leqq c^{* *}\left(\delta^{2}+\delta\right) .
$$

If we choose $\delta>0$ such that $c^{* *}\left(\delta^{2}+\delta\right)<\varepsilon / 2$, then in view of $(5.8)$ and $(5.9)$,

$$
\left\{\int_{\Omega}\left[\varrho\left(\left|\nabla u_{n}^{1}\right|^{2}\right)-\varrho\left(\left|\nabla u_{n}\right|^{2}\right)\right]^{2}\left|\nabla w_{n}{ }^{1}\right|^{2} d x\right\}^{1 / 2}<\varepsilon
$$

for $n \geqq n_{0}$, which concludes the proof

\section{Acknowledgement}

We are grateful to Prof. Dr. J. PoLÁŠEk from the Technical University in Prague, who brought us to this difficult but interesting problem and expressed always his interest in the results of our work. Further, we thank very much to Dr. K. KozeL from the Technical University in Prague for the survey on the numerical simulation of transonic flows by the finite-difference method. We are also obliged to Dr. J. Mandel from the. Charles University in Prague for interesting and inspiring discussions on nonconvex variational problems and minimization techniques.

\section{REFERENC̃ES}

[1] Açon, S., Dougtis, A., and L. Nlrenberg. Estimates near the boundary for solutions of elliptic partial differential equations satisfying general boundary conditions I, II. Comm. Pure Appl. Math. 12 (1959), 623-727 and 17 (1964), 35-92:

[2] Arlinger, B.: Axisymmetric tránsonic flow computations using a multigrid method. Lecture Notes in Physics 141 (1981), 55-60.

[3] Bristeau, M. O., Glowinski, R., Periadx, J., Perrier, P., and O. Pironneau: On the numerical solution of nonlinear problems in fluid dynamics by least squares and finite element methods. (I) Least square formulations and conjugate gradient solution of the continuous problems. Comp. Meth. Appl. Mech. Eng. 17/18 (1979), 619-657.

[4] Bristeau, M. O., Glowinski, R., Perraux, J., Perrië, P., Porrier, G., and O. PronNEAU: Application of optimal control and finite element methods to the calculation of transonic flows and incompressible viscous flows. In: Num. Meth. in Appl. Fluid Dynamics (Ed.: B. Hunt). London: Academic Press 1980, 203-312.

[5] Chatrot, J. J.; Guid-Roux, J., and J. Laminie: Finite element calculation of steady transonic flow in nozzles using primary variables. Lecture Notes in Physics 141 (1981), $107-112$.

[6] Cole, J. D., and E. M. Murnias: Calculation of plane steady transonic flows. Amer. Inst. for Aeronautics and Astronautics (AIAA) Journal 9 (1971), 199-206. 
[7] Decosisck, H., and C. Hrrscr: Transonic flow calculations with higher finite elements. Lecture Notes in Physics 141 (1981), 138-143.

[8] Feistauer', M.: Minimization of nonconvex functional and its application to the numerical solution of transonic flows by the finite element method. In: Proc. conf. Num. Meth. in Cont. Mech. Žilina (ČSSR): Dum techniky ČSVTS (Czech. Soc. Sci. 'Techn.) 110 (1978), $69-75$ (in Czech).

[9] Feistauer, M. : Mathematical study of three-dimensional axially symmetric stream fields of an ideal fluid. In: Methoden und Verfahren der math. Phys., Bd. 21 (Eds: B. Brosowski. and E. Martensen). Frankfurt/a. M.-Bern: P. D. Lang-Verlag 1981, 45-61.

[10] Feistader, M.: Numerical solution of non-viscous axially symmetric channel flows. In: Methoden und Verfahren der math. Phys., Bd. 24 (Eds: E. Meister; K. Nickel and J. Polášek). Frankfurt/a. M. - Bern: P. D. I.ang-Verlag 1982, 65-78.

[11] Feistauer, M.: On irrotational flows through cascades of profiles in a layer of variable thickness. Apl. mat. 29 (1984), 423-453.

[12] Feistaufr, M., and M. Hoxer: Solution of an axially symmetric flow by the finite element method. Strojnícky čas. 34 (1983), 607-621 (in Czech).

[13] Feistalier, M., and J. Ŕmíxek: Solution of subsonic axially symmetric stream fields. Apl. mat. 20 (1975), 266-279:

[14] Fučík, S., Krratochvíl, A., and J. Nfč́s: Kačanov-Galerkin method. Comment. Math., Univ. Carolinae 14 (1973), 651-659.

[15] Fưč́r, S., NečAs, J., and V. SoJčEK: Einführung in die Variationsrechnung (TeubnerTexte zur Mathematik: Bd. 11). Leipzig: BSB B. G. Teubner Verlagsgesellschaft 1977.

[16] Garabedin, P. R., and D. G. Korn: Analysís of transonic airfoils. Comm. Pure Appl. Math. 24 (1971), 841-851.

[17] Glowrsski, R.: Lectures on Numerical Methods for Nonlinear Variational Problems. Berlin-Heidelberg-New. York: Springer-Verlag 1981.

[18] Glowisski, R., and O. Piroxinfau: On the computation of transonic flows. In: Proc. Japan-France Seminar Funct. Anal. Num. Anal. (Ed.: H. Fujita). 'Tokyo and Kyoto 1978, $143-173$.

[19] Glowinski, R., Lions, J. L., and R. Trémoliéres: Numerical Analysis of Variational Inequalities (Studies in Math. and its Appl.: Vol. 8). Amsterdam : North-Holland 1981.

[20] Janesos, A.: Iterative solutions of transonic flows over airfoils and wings, including flows at Mach 1. Comm. Pure Appl. Math. 27 (1974), 283-309.

[21] J AM fSON, A.: Numerical computation of transonic flows with shock waves. In: Symposium Transonicum II (Eds: K. Oswalitseh and D. Rues). Berlin-Heidelberg-New York: Springer Verlag 1975. .,

[22] Jameson, A.: Acceleration of transonic potential flow calculations on arbitrary meshes by the multiple grid method. Amer. Inst. for Aeronautics and Astronautics (AIAA) Paper 79-1458' (1979).

[2:3] Kozel, K., Poláš́fk, J., and M. Vavřrncová: Numerical solution of transonic flow through a cascade with slender profiles. Lecture Notes in Physics 90 (1979), '3333 to 338.

[24] Kozel, K., Polášsk, J., and M. VavǩrNcová: Numerical solution of tranșonic shear flows past thin bodies. Lecture Notes in Physics 170 (1982), 303-307.

[25] Meyprs, N. G.: An $L^{p}$-estimate for the gradient of solutions of second order elliptic diyergence equations. Ann. Scuola Norm. Sup. Pisa (3) 17 (1963), 189-206.

[26] Múat, F.: L'injection du cône positif de $\mathrm{H}^{-1}$ dans $w-1 / q$ est compacte pour tout $q<2$. J. Math. Pures Appl. (9) (30 (1981), 309-322.

[27] Nečss, J.: Lẹs méthodes directes en théorie des équations elliptiques. Praguc: Academia 1967.

[28] NeČAs, J.: Introduction to the Theory of Nonlinear Elliptic Equations (Teubner-Texte zur Mathematik: Vol. 52). Leipzig: BSB B. G. Teubner Verlagsgesellschaft 1983.

[29] NeČAs, J., and I. HLAvíček : Mathematical Theory of Elastic and Elasto-Plastic Bodics: An Introduction. Amsterdam-Oxford-New York: Elsevier 1981.

[30] Oršulík, V.: 'Transonic irrotationăl flow of an ideal compressible fluid (Thesis). Prague: Fac. of Math. and Phys., Charles Univ. 1978 (in Crech).

[31] Prriaux, J:: Three- dimensional analysis of compressible flows with the finite element method. Int. J. Num. Meth. Eng. 9 (1975), 739-763. 
[32] Polrikr, G. ¿ Traitement numériques en éléments finis de la condition d'entropie des équations transsoniques (Thesis). Paris VI: L'Université Pierre et Marie Curie 1981.

'[33] ВАн̆неРг, М. М.: Вариациониы метод и метол монотонных операторов в теории нелинейных уравнений. Москва: Изд-во Наука 1972.

Manuskripteingang: 09. 07. 1984

\section{VERFASSER}

Prof. Dr. Mrios̀lav Feistauer and Prof. Dr. Jindřich Nečas

Department of Applied Mathematics,

Faculty of Mathematics and Physics, Charles University

ĆSSR-11800 Praha 1, Malostranské n. 25 